\title{
Trabalho imaterial e trabalho docente
}

Immaterial Labor and Teachers' work

\author{
Álvaro Moreira Hypolito* \\ Universidade Federal de Pelotas \\ Paulo Eduardo Grishcke** \\ Instituto Federal Sul-Rio-grandende
}

Resumo $\quad \mathrm{O}$ artigo discute a tendência do trabalho da sociedade capitalista no contexto da reestruturação produtiva contemporânea, argumentando a favor da perspectiva que sustenta a tendência de aumento e consolidação da forma de trabalho imaterial, como modo hegemônico na sociedade do conhecimento. Discorre sobre as formas do trabalho no setor de serviços e discute as diversas formas do trabalho imaterial na sociedade atual. Por fim, discute o trabalho docente como uma forma de trabalho imaterial que está relacionada com aspectos subjetivos e emocionais da identidade docente. É um texto de discussão teórica sobre o trabalho docente no contexto atual do capitalismo.

PALAVRAS-CHAVE: Trabalho, Trabalho imaterial, Trabalho docente.

Abstract This article discusses some trends of the labor in the capitalist society in the context of restructuring of contemporary modes of production, arguing in favor of a point of view that understands the trend of increasing and consolidating form of immaterial labor as a hegemonic type of labor in the knowledge society. It also argues on forms of labor in the tertiary sector and discusses several forms of immaterial labor in the current society. Finally, this paper discusses teachers' work as one form of immaterial labor related with subjective and emotional aspects of teachers' identity. It is a theoretical discussion on teachers' work in the context of contemporary capitalism.

KEYWORDS: Labor, Immaterial labor, Teachers' work. 


\section{O trabalho imaterial como tendência - uma introdução}

As mutações políticas, culturais e econômicas, do final do século $X X$, produziram um período de profundas indefinições no sistema mundial como um todo. Esse período foi denominado, por Santos (2002), de transição paradigmática, uma época de profundas indefinições jurídicas, científicas e culturais em que os consensos, as formas de ser, fazer, pensar e estar no mundo se desfazem. Uma época de transição que se reflete nas formas de poder e nas formas de conhecimento. Uma época de crise de confiança na ciência, provocada, principalmente, pela sua privatização e mercantilização. Também uma época que abre um mundo de possibilidades de mudanças tanto políticas quanto culturais (GANDIN; HYPOLITO, 2003).

Uma falta de consenso que se reflete na denominação da nova sociedade que se forma, para alguns, seria uma sociedade pós-industrial, pois teria como base os serviços e informação (BELL, 1977). Para outros, é entendida como uma sociedade do conbecimento (DRUCKER, 2002) ou sociedade informacional (CASTELLS, 1999), na qual a produtividade e a competitividade da economia dependeriam, cada vez mais, da sua capacidade de gerar, processar e aplicar de forma eficiente a informação baseada em conhecimentos.

Outra denominação bastante utilizada para se referir às mudanças nas formas de produção é o pós-fordismo. Não significa que o fordismo tenha desaparecido, muito pelo contrário, porquanto, na sociedade contemporânea, convivem formas tayloristas, fordistas, toyotistas e suas hibridizações, tanto na organização da produção como na gestão da força de trabalho. De qualquer modo, seja lá o nome que se dê ao momento contemporâneo, o que há de consenso é que o processo de globalização da economia e as reestruturações econômicas e produtivas provocaram uma radical transformação nas estruturas e nos fatores de produção das organizações no mundo inteiro (GORZ, 2005).

Essas reestruturações traduziram-se em mudanças dramáticas, tanto no uso da força de trabalho quanto nos processos e nos mercados de trabalho. Cabe salientar que os efeitos se traduziram, conforme Castells (1999), em um declínio no emprego industrial, queda dos salários reais, aumento da desigualdade e instabilidade no emprego, precarização do trabalho e desvalorização da mão de obra.

Os sindicatos de trabalhadores foram enfraquecidos pelo relaxamento ou pela falta de cumprimento da legislação trabalhista por parte das empresas e dos governos neoliberais, pela redução de conflitos entre capital e trabalho, devido ao aumento do número de trabalhadores excedentes desempregados e subempregados, pela intensificação da competição entre os trabalhadores por empregos cada vez mais escassos e pela utilização, por parte das empresas, de novas estratégias de gestão da força de trabalho (BURBULES; TORRES, 2004). O resultado disso, na visão de Castells (1999), foi que a mão-de-obra encontra-se "desagregada em seu desempenho, fragmentada em sua organização, diversificada em sua existência e dividida em sua ação coletiva" (CASTELLS, 1999, p. 502). 
Resumindo, para os trabalhadores, o processo de reestruturação produtiva trouxe consigo o desemprego estrutural e uma crescente heterogeneidade e fragmentação da classe trabalhadora (ANTUNES, 1998; ANTUNES; ALVES, 2004). A ponto de o cenário atual aproximar-se do que Gorz (1987) chama de sociedade do desemprego, "de um lado uma massa crescente de desempregados permanentes; de outro, uma aristocracia de trabalhadores protegidos e, entre os dois, um proletariado de trabalhadores precários" (GORZ, 1997, p. 12). Trabalhadores precários que, por sua vez, formam o que Pochmann (1998) denomina de desemprego disfarçado, pois o trabalhador, ao não conseguir uma vaga no mercado formal, passa a exercer atividades temporárias, ou a trabalhar como autônomo, sem amparo da legislação trabalhista e em condições precárias.

Nesse mundo de incertezas, o setor de serviços teve um crescimento expressivo ao absorver parte dos trabalhadores demitidos pela indústria (ANTUNES; ALVES, 2004). Enquanto a quantidade de trabalhadores empregados diretamente pelo setor industrial diminuía, no setor de serviços apresentava-se um elevado crescimento em áreas tão diversas como as relacionadas com a produção, como também com serviços pessoais e sociais (OFFE, 1995; MATTOSO, 1995; CASTELLS, 1999).

Ocorre, assim, uma crescente diversificação desse setor como fonte de trabalho e renda que engloba um grande número de atividades, tais como comércio, transportes, publicidade, informática, telecomunicações, turismo, educação, saúde, cuidados, recreação e entretenimento, finanças, seguros, segurança privada, limpeza e conservação, administração pública, organizações não-governamentais e muitas outras. Atividades que são inventadas e reinventadas, quase que diariamente, por uma força de trabalho envolvida em "comunicação, cooperação, dedicação e reprodução de cuidados", que ocupa "posição cada vez mais central nos esquemas de produção capitalista como na composição do proletariado" (HARDT; NEGRI, 2004, p. 72).

Assim, o setor de serviços, conhecido também como setor terciário da economia, assume importância crucial na sociedade pós-fordista globalizada e, junto com ele é valorizada uma forma de trabalho antes considerada improdutiva em muitas modalidades: o trabalho imaterial.

Conforme Alves (2000), na sociedade contemporânea, é a informação que constitui os fluxos dos novos espaços de produção e reprodução social. Ela estrutura, cada vez mais, a produção do capital, seja na indústria propriamente dita, seja nos serviços capitalizados. A produção de mercadorias necessita, sem sombra de dúvidas, do trabalho informacional e comunicativo, que lhe agrega valor efetivo. Dessa forma, a materialidade da mercadoria está prenhe da imaterialidade do trabalho vivo.

A passagem para o pós-fordismo indica a instalação de novas relações entreas forças de trabalhoe a sociedade.O paradigma fundamental do pós-fordismo, como modo de produção largamente socializado, é baseado na comunicação social 
de atores flexíveis e móveis, pois é ela que alimenta a inovação, as tecnologias da informação e a chamada economia do conhecimento. Este novo paradigma seria, portanto, o do trabalho imaterial (COCCO, 2007).

Para Hardt e Negri (2005), em qualquer sistema econômico sempre existe um tipo de trabalho que exerce influência sobre os outros. Essa forma hegemônica funciona como um vórtice que gradualmente transforma as outras formas de trabalho, fazendo-as adotarem suas qualidades centrais. Foi assim com o trabalho industrial que, gradualmente, a partir do século XIX, foi se tornando hegemônico sobre o trabalho agrícola. O trabalho industrial foi lentamente transformando todas as instituições sociais à sua lógica. Mas, nas últimas décadas do século $X X$, o trabalho industrial vem perdendo sua hegemonia, surgindo, em seu lugar, o trabalho imaterial, o trabalho que cria produtos imateriais como o conhecimento, a informação, a comunicação.

Entretanto, esta afirmação pode levar a uma série de questionamentos sobre a ambiguidade do termo trabalho imaterial. Hardt e Negri tentam esclarecer: "Devemos enfatizar que o trabalho envolvido em toda produção imaterial continua sendo material - mobiliza nossos corpos e nossos cérebros, como qualquer trabalho. O que é imaterial é o seu produto" (2005, p.150). E quanto à alegada hegemonia do trabalho imaterial sobre o material, em termos globais, os autores explicam:

Quando afirmamos que o trabalho imaterial tende para a posição hegemônica, não estamos dizendo que a maioria dos trabalhadores do mundo atualmente produz primordialmente bens imateriais. (...) O trabalho imaterial constitui uma minoria do trabalho global, concentrando-se em algumas das regiões dominantes do planeta. Nossa tese, isto sim, é que o trabalho imaterial tornou-se hegemônico em termos qualitativos, tendo imposto uma tendência a outras formas de trabalho e à própria sociedade!. (HARDT; NEGRI, 2005, p. 151)

Por meio da informatização da produção de bens e serviços, o conteúdo do trabalho, que era essencialmente material, estaria mudando para o imaterial. Com as novas tecnologias de informação, a força física cede lugar às competências cognitivas e o objetivo final do processo de trabalho passa a ser o de acumular conhecimentos, adicionando um valor derivado da criatividade intelectual. Dessa forma, o trabalho humano teria sua natureza alterada, na medida em que se move rumo à nova economia global informacional (CASTELLS, 1999).

\section{O trabalho em serviços}

Para Marx, o serviço é "uma expressão para o valor de uso particular do trabalho, na medida em que este não é útil como coisa, mas como atividade" (MARX, 1980, p. 486). A categoria atividade é central na compreensão do ser humano como sujeito de ação e de práxis, sendo a atividade "parte de um projeto de transformação da natureza e dos homens" (CODO; SAMPAIO; HITOMI, 1993, p. 92). O serviço, por ser uma categoria que não trabalha diretamente com a matéria, 
com a "transformação imediata da natureza em bem material e durável", mas com "relações sociais organizadas pela comunicação", constituir-se-ia, assim, em trabalho imaterial: "trabalho que produz um bem imaterial, como serviço, produto cultural, conhecimento ou comunicação" (HARDT; NEGRI, 2004, p. 311). Para Marx, a produção não-material ou imaterial pode ser de dois tipos, por um lado, pode resultar

[...] em mercadorias, valores de uso, que possuem uma forma autônoma, distinta dos produtores e consumidores, quer dizer, podem existir e circular no intervalo entre produção e consumo como mercadorias vendáveis, tais como livros, quadros, em suma, todos os produtos artísticos que se distinguem do desempenho do artista executante. (...). (MARX, 1980, p. 403)

E, por outro lado, "a produção é inseparável do ato de produzir, como sucede com todos os artistas executantes, oradores, atores, professores, médicos, padres, etc." (...) (MARX, 1980, p. 403).

No entanto, para Marx (1980), em seu tempo, nestes tipos de atividades a produção capitalista só se aplicaria de forma muito limitada. Mas, na atualidade, essa afirmativa seria discutível, uma vez que, ao mesmo tempo em que se presencia uma enorme precarização do trabalho em todas as suas formas, também se nota um aumento das atividades ditas intelectuais, quer nos setores industriais mais informatizados, quer nas áreas envolvidas pelo setor de serviços ou nas comunicações, entre outras, nas quais a comunicação e a informação estão desempenhando um novo papel na produção (CASTELLS, 1999). Conforme Gorz (2005), o fornecimento de serviços e o trabalho imaterial tornam-se a forma preponderante de trabalho na contemporaneidade, na qual "o trabalho material é enviado à periferia do processo de produção capitalista. O coração, o centro de criação de valor, é o trabalho imaterial" (GORZ, 2005, p. 19).

Muitas vezes, para alguns autores, a atividade de serviço ou o trabalho imaterial foi caracterizado como trabalho improdutivo por não estar ligado diretamente à produção de bens materiais. Mas, para Marx (1978), o fato de um trabalho ser produtivo ou improdutivo diz respeito somente às relações sob as quais os trabalhadores são organizados e não à natureza do produto. Dessa forma, é produtivo todo trabalho que produza mais-valia ou, em outras palavras, "o trabalho que seja consumido diretamente no processo de produção com vistas à valorização do capital" (MARX, 1978, p. 481). Por conseguinte, artistas ou professores, da mesma maneira que operários ou engenheiros, podem ser empregados pelos capitalistas com vistas ao lucro. Para o capitalista "(...) a natureza do valor de uso e o caráter do trabalho concreto utilizado é totalmente indiferente (...) o trabalho produtivo é puramente meio de obter dinheiro, de produzir mais-valia" (MARX, 1978, p. 486).

Para Braverman, o trabalho na produção de bens não está separado do trabalho aplicado na produção de serviços, já que"ambos são formas de produção de mercadorias, e produção em base capitalista, cujo objetivo é a produção não apenas 
de valor de troca, mas de valor excedente para o capitalista" (BRAVERMAN, 1987, p. 347).

Para Lojkine (1995) "(...), a oposição entre a classe dos produtores [de mais-valia] e a classe dos improdutivos dá cada vez menos conta das relações que atualmente se estabelecem entre a produção e a informação, (...)" (LOJKINE, 1995, p. 12). Assim, a revolução informacional, "subverte a relação que cada assalariado mantém com o trabalho produtivo e improdutivo" (Ibidem, p. 280) e coloca exposta "(...) uma tendência irreversível para abrir todas as atividades produtivas às funções de serviços e todas as atividades de serviço às funções produtivas" (Ibidem, p. 289).

Em síntese, numa sociedade na qual a subsunção do trabalho ao capital é cada vez mais real, de modo que a força de trabalho venha a ser, ela mesma, incluída e como que transformada em capital. Em uma sociedade em que é praticamente impossível ficar-se fora das relações capitalistas de produção e acumulação, torna-se difícil distinguir trabalho produtivo de improdutivo. De maneira que, no mundo contemporâneo, toda a forma de trabalho, seja ele "trabalho material ou imaterial, intelectual ou físico, produz e reproduz a vida social, e durante o processo é explorado pelo capital" (HARDT; NEGRI, 2004, p. 426).

\section{As diversas formas de Trabalho Imaterial}

Hardt e Negri (2004) apontam três tipos de trabalho imaterial que movimentam atualmente o setor de serviços. O primeiro estaria ligado à produção industrial, que foi informatizada e incorporou tecnologias de comunicação, alterando, assim, o próprio processo de produção. A principal mudança na estrutura desse modelo envolveu o sistema de comunicação entre a produção e o consumo de mercadorias, no caminho da informação entre a fábrica e o mercado. Por manter o estoque zero, as mercadorias são produzidas pelas fábricas de acordo com a demanda dos mercados. Dessa forma, a informação passa a desempenhar um papel fundamental nos processos de produção que, como nos serviços, baseiase na permanente troca de conhecimentos e de informações.

Este modelo industrial de produção enxuta e flexível, junto à sua filosofia da qualidade total, no entender de Gorz (2005), fez com que a atividade fabril fosse vista como um serviço, de maneira que o trabalho material da produção mescla-se, cada vez mais, com o trabalho imaterial da prestação de serviços. É a relação de serviço, ou em outras palavras, a comunicação entre as pessoas que se expande nos espaços de produção, nos quais, "progressivamente, se impõem à relação direta entre prestadores de serviço e usuários" (LOJKINE, 1995, p. 309).

Nesse contexto, o trabalho parcelarizado, repetitivo e especializado, na linha de produção em massa, é substituído pelo trabalho comunicativo, informacional e polivalente dos grupos semi-autônomos nas células de produção flexíveis. O trabalhador qualificado e especializado é substituído pelo trabalhador 
competente e multifuncional. A disciplina rígida e a vigilância hierárquica do taylorismo/fordismo são substituídas pela gestão democrática, pelo autocontrole e pela autonomação $o^{1}$ do trabalho na produção enxuta. A utilização massiva da automação implica em cada vez menos trabalho manual e exige cada vez mais manipulação simbólica. Assim, exige-se do trabalhador capacidade de diagnosticar e solucionar problemas, de tomar decisões, de intervir no processo de trabalho, de trabalhar em equipe e de auto-organização de modo a enfrentar situações em constantes mudanças.

Como resultado dessas transformações tem-se valorizado enormemente o trabalho intelectual e cognitivo. A cognição, a capacidade da organização empresarial em aumentar as fontes de conhecimento, passa a constituir-se como um elemento vital num sistema econômico cuja inovação e a flexibilidade são de importância fundamentais para a sobrevivência empresarial.

Um segundo tipo de trabalho imaterial estaria ligado às tarefas que Reich (1994) denomina de simbólico-analiticas, nas quais os trabalhadores são envolvidos em serviços especializados de identificação e solução de problemas, pesquisa e desenvolvimento de produtos, publicidade, consultoria, assistência a clientes, promoção de vendas, entre outros.

Para Reich (1994), os analistas simbólicos identificam e solucionam problemas e promovem a venda de soluções por meio da manipulação de símbolos, "simplificam a realidade por meio de imagens abstratas que podem ser rearranjadas, embaralhadas, experimentadas e comunicadas" (REICH, 1994, p. 165).

Para Hardt e Negri (2005), esse tipo de trabalho imaterial é prioritariamente intelectual ou lingüístico, na medida em que produz idéias, símbolos, códigos, textos, formas lingüísticas, imagens e outros produtos do gênero. Nele se encaixariam os escritores, os jornalistas, os pesquisadores e professores universitários, os programadores visuais, os analistas de marketing, os produtores de software, etc.

A terceira e maior categoria, que se inclui no trabalho imaterial, segundo Hardt e Negri (2004), seria ocupada pelos denominados trabalhadores relacionais, aqueles que se envolvem com a comunicação, com a produção de cuidados e com a manipulação de afetos, solicitando, para isso, contato e interação humanos, que tanto podem ser reais, como virtuais. Para Hardt e Negri (2005), os afetos, ao contrário das emoções que são fenômenos puramente mentais, envolvem igualmente o corpo e a mente. $O$ trabalho afetivo é o trabalho que produz ou manipula afetos como a sensação de bem estar, tranqüilidade, satisfação, excitação ou paixão. A maior parte dos serviços que envolvem trabalho relacional combina a comunicação com um elemento afetivo. Nessa categoria estariam os trabalhadores das áreas da saúde, da educação, dos serviços pessoais, do entretenimento, da comunicação e etc.

Segundo Gorz (2005), o trabalho relacional e afetivo gera um problema para o capital. $O$ problema é que a maioria dos trabalhos relacionais assim como dos 
trabalhos imateriais, em geral, não podem ser inteiramente ensinado. O seu saber não pode ser reduzido a um conhecimento regular, formal, pois preserva a marca da pessoa que o exerce. O cuidar dos outros subentende, necessariamente, cuidado de si, produção de si e doação de si. Isso é patente nos serviços relacionais com a educação, cuidados e assistência, mas também em outros trabalhos imateriais como nos ofícios artísticos, na moda, no design e na publicidade.

Para Gorz (2005), a maior parte dos saberes ativados pelo trabalho imaterial não existe senão em sua prática viva. Esses saberes não podem ser destacados dos indivíduos que os praticam. Esses saberes são resultado da experiência de vida em sociedade e não podem ser assimilados ou expropriados pelo capital:

O valor de um serviço é, pois, tão menos mensurável quanto maior seja a parcela de doação e de produção de si, ou seja, quanto mais seu caráter incomparavelmente pessoal lhe confira um valor intrínseco que prevalece sobre seu valor de troca normal. No limite, a competência pessoal transcende a norma das atribuições profissionais, e aparece como uma arte cujo prestador é um virtuose. Seu nome é similar a um nome de marca, de uma firma. Imensuráveis e incomparáveis, suas prestações [de serviço] se tornam uma fonte de renda de monopólio. (GORZ, 2005, p. 33)

Conforme Gorz (2005), o que diferencia os trabalhadores, no sistema de produção taylorista/fordista, dos trabalhadores do sistema pós-fordista é que os primeiros foram deliberadamente privados de seus saberes e de suas habilidades, despojados de seus hábitos e submetidos a uma divisão fragmentada do trabalho, cujo objetivo principal era conseguir que o trabalhador executasse, sem questionar, o comando que a maquinaria Ihe transmitia. Já os trabalhadores pós-fordistas devem ingressar no processo de produção com toda a bagagem cultural adquirida fora do trabalho, pois, além de seus conhecimentos e habilidades, a produção agora necessita da sua criatividade, da sua capacidade de improvisação e de sua colaboração e engajamento nas finalidades da empresa.

Para Cocco (2007), trata-se de um trabalhador dotado de uma capacidade de gestão das relações sociais que supera o perímetro da empresa; suas qualificações dependem diretamente da sua capacidade de desenvolver, ao mesmo tempo, atividades culturais, informacionais e gerenciais. O trabalhador agora deve produzir, inovar, coordenar e consumir. É ele quem produz o conteúdo cultural e informacional da mercadoria e seu ciclo de produção e reprodução. $A$ emergência do trabalho imaterial determina, portanto, uma transformação radical dos papéis, das relações e das hierarquias que caracterizam e estruturam o sistema produtivo.

A desespecialização do trabalho industrial, com a conseqüente substituição do operário parcelar pelo operário polivalente e multiqualificado que trabalha criativamente em equipe, a utilização cada vez maior, por parte das empresas, de trabalhadores terceirizados e a própria expansão do setor de serviços 
como um todo, no qual o trabalho é mais flexível e multifuncional, colocou em cheque a rigidez do conceito de qualificação profissional. O conceito de qualificação profissional refere-se, principalmente, à análise do posto de trabalho e à formação teórica do trabalhador de maneira a adequá-lo a ocupar aquela determinada função, tendo nos diplomas e certificados principais documentos de validação dessa formação (RAMOS, 2002).

Cabe dizer que, a partir do final dos anos 80 , como parte do processo de reestruturação produtiva, o conceito de qualificação vai perdendo força e, em seu lugar, surge o de competência que, para Zarifian (2001), pode ser compreendido como a capacidade que os trabalhadores têm para enfrentar situações e acontecimentos próprios de um determinado campo profissional, "uma combinação de conhecimentos, de saber fazer, de experiências e comportamentos que se exerce em um contexto preciso".

Para Gorz (2005), todo trabalho, seja na produção industrial seja no setor de serviços, depende de um determinado tipo de saber que não é composto por conhecimentos formalizados ou aprendidos nas escolas. Ao contrário, o que foi revalorizado foram os saberes da experiência. Os saberes tácitos, assim como o discernimento, a capacidade de organização, de comunicação e de coordenação, "formas de um saber vivo que pertencem à cultura do cotidiano" (GORZ, 2005, p. 9).

No entender de Ramos (2002), ao se valorizar os saberes da experiência, os saberes tácitos, os saberes sociais adquirem importância frente aos saberes formais. A qualificação profissional deixa de ser expressa simplesmente em função dos conceitos técnico-científicos de que o trabalhador é portador. Passa a interessar "a pessoa funcional, ou seja, aquela que mobiliza seus atributos cognitivos e sócioafetivos para obter resultados" (RAMOS, 2002, p. 288). O trabalho não é mais um dado objetivável, padronizado e não pode ser classificado em meras listagens de tarefas.

Os saberes do trabalho vão além das competências técnicas e passam a incorporar campos que não eram valorizados, como a capacidade de trabalhar em equipe, a flexibilidade e a polivalência, entre outros. O que é valorizado no trabalhador são as qualidades de comportamento, as qualidades comunicativas e imaginativas, o envolvimento pessoal na tarefa a desenvolver e completar. Todas essas qualidades são"habitualmente próprias dos prestadores de serviços pessoais, dos fornecedores de um trabalho imaterial impossível de quantificar, estocar, homologar, formalizar e até mesmo de objetivar" (GORZ, 2005, p. 17).

Nunca, em qualquer outra fase do desenvolvimento econômico da humanidade, os trabalhadores viram-se em meio a tantas exigências cognitivas, psicológicas e comportamentais. As funções do trabalhador se multiplicam e não é suficientemente claro o que se espera deles (BARBOSA, 2005). Soma-se a isso a idéia de que o trabalhador, agora, também deve desenvolver a sua empregabilidade, de maneira a ficar preparado para a mobilidade permanente entre diferentes 
ocupações numa mesma empresa ou entre empresas, para o subemprego ou para o trabalho autônomo (RAMOS, 2002).

Os empregos bem remunerados, estáveis e para toda a vida, são cada vez mais escassos, e tendem a desaparecer (RIFKIN 1995; OFFE, 1995). Conforme Gorz (2005), a visão neoliberal do mercado de trabalho tratou de desenvolver uma nova forma de combater o desemprego: transformar todos os trabalhadores em empresas individuais de prestação de serviços. Logo, para ter empregabilidade "a pessoa deve, para si mesma, tornar-se uma empresa; ela deve se tornar, como força de trabalho, um capital fixo que exige ser continuamente reproduzido, modernizado, alargado, valorizado" (GORZ, 2005, p. 23).

Multiplicam-se, nas prateleiras das bibliotecas, livros como Um mundo sem empregos (1995), Você \& Cia (1998), de Willian Bridges, ou Empregabilidade: o caminho das pedras, de José Augusto Minarelli (1995). Esses autores procuram mostrar as vantagens de empresariar a própria vida profissional e, por conseqüência, tornarem-se "tão flexíveis quanto as empresas" (MINARELLI, 1995, p. 19), pois, "agora você também vai ser um negócio", e para isso é "importante ver-se como alguém que está rodeado por um mercado, mesmo fazendo parte da folha de pagamento de uma organização" (BRIDGES, 1995, p. 115). No empresariamento de si, "a diferença entre sujeito e empresa, entre a força de trabalho e capital deve ser suprimida. A pessoa deve, para si mesma, tornar-se uma empresa" (GORZ, 2005, p. 23).

Sob esta ótica, ter empregabilidade é ser empresário de si. O trabalhador deve pensar "como um fornecedor externo de serviços e adotar a mentalidade de vendedor" (BRIDGES, 2005, p. 115), "precisa empresariar o seu talento" e sempre se lembrar que sua segurança profissional "decorre da (sua) capacidade de gerar trabalho e renda permanentemente". "O emprego poderá faltar, mas não o trabalho nem a perspectiva de remuneração" (MINARELLI, 1995, p. 20). Nessa concepção, conforme Gorz (2005), cada pessoa será uma empresa individual de prestação de serviços: cada um deverá ser "responsável por sua saúde, por sua mobilidade, por sua adaptação aos horários variáveis, pela atualização de seus conhecimentos. Cada um deverá gerir seu capital humano ao longo de sua vida" (GORZ, 2005, p. 24).

As organizações, para funcionarem, necessitarão de apenas um pequeno número de trabalhadores estáveis. O restante será formado por uma massa de trabalhadores estagiários, substitutos, temporários ou autônomos. Além do mais, as organizações livrar-se-ão de grande parte do custo de reprodução da força de trabalho, pois os custos da formação contínua, do seguro-saúde e da pensão ou aposentadoria serão pagos pelos próprios trabalhadores. Por sua vez, com o fim do regime salarial, a empresa compra os serviços, negociando o preço pela tarefa ou pelo tempo ocupado, põe os trabalhadores em concorrência uns com os outros, faz variar fortemente o volume de trabalho sem se preocupar com a duração do dia de trabalho, sem ter de conceder indenizações, licenças ou férias. No ideal neoliberal, "o futuro pertence aos auto-empreendedores cujo número cresce rapidamente" (GORZ, 2005, p. 24). 
Pelo empresariamento de si, toda atividade pode tornar-se um negócio. Não importa se você é médico, cientista ou professor, "sempre que existem necessidades, pessoas e vida, pode haver trabalho e possibilidade de ganhar. Tudo é mercado" (MINARELLI, 1995, p. 27). A fronteira entre o que passa fora do trabalho e o que ocorre dentro do trabalho apaga-se, agora "toda atividade deve poder tornar-se um negócio (...), tudo se torna mercadoria, a venda de si se estende a todos os aspectos da vida" (GORZ, 2005, p. 25). Em síntese, essa seria a visão neoliberal para o futuro do trabalho: "abolição do regime salarial, autoemprendimento e subsunção de toda vida pelo capital, com o qual cada um se identificará inteiramente" (Idem).

O tempo e o espaço são comprimidos. Acelera-se o tempo de giro na produção em troca de acelerações na troca e no consumo. Sistemas de comunicação e de fluxo de informações associados a técnicas racionalizadas de produção possibilitam a circulação de mercadorias em uma velocidade nunca antes imaginada. Bancos eletrônicos e dinheiro de plástico aceleram o fluxo de dinheiro no sentido inverso. $O$ espaço é reduzido pela velocidade das comunicações e das informações. Chegamos ao outro lado do mundo a um simples toque na tecla do computador. $\mathrm{O}$ tempo de vida dos produtos é reduzido de forma absurda através da volatilidade e efemeridade da moda. Cria-se uma ênfase nos valores e virtudes do instantâneo e do descartável. Tudo pode ser jogado fora, valores, estilos de vida, relacionamentos, reputações, edifícios, lugares, pessoas, modos de agir e de ser (HARVEY, 1992).

Quando o trabalho se move para fora dos muros das fábricas é cada vez mais difícil manter uma medida do dia de trabalho e separar o tempo de trabalho do tempo de lazer (HARDT e NEGRI, 2004). Com as novas tecnologias de comunicação, como a internet e o telefone celular, já não há mais fronteiras claras entre o trabalho e a vida familiar. É no ciberespaço, em um contexto de novas possibilidades de comunicação, de flexibilidade, de "um espaço fluido e de um tempo dentro do tempo", que produzem novas formas de organização do capitalismo e modos mais flexíveis de acumulação do capital. Com a internet, agora é possível trabalhar em casa. Os horários flexibilizados e os deslocamentos reduzidos reforçam, no trabalhador, o sentimento de liberdade. $O$ controle do trabalho por meio da gestão e por objetivos, substitui o relógio ponto e reforça o sentimento de responsabilidade, repassando o controle do tempo para o próprio trabalhador (MILL, 2006).

\section{Trabalho docente: imaterial, relacional e afetivo}

Tardif e Lessard (2005), ao analisarem o trabalho docente como trabalho imaterial, incluíram os docentes no rol dos trabalhos relacionais (HARDT; NEGRI, 2004). Para Tardif e Lessard (2005) a docência é uma "forma particular de trabalho sobre o humano, ou seja, uma atividade em que o trabalhador se dedica ao seu 'objeto' de trabalho, que justamente outro ser humano no modo fundamental de integração humana" (p. 9). 
Os autores, ao definirem um quadro de análise da profissão docente hoje, afirmam que "longe de ser uma ocupação secundária ou periférica em relação à hegemonia do trabalho material", o trabalho docente por ser, ao mesmo tempo, cognitivo e interativo "constitui uma das chaves para a compreensão das transformações atuais da sociedade do trabalho" (Ibidem, p. 17).

A tese de Tardif e Lessard apóia-se, basicamente, em quatro constatações: a primeira é que a categoria dos trabalhadores de bens materiais está em queda em todas as sociedades modernas avançadas, ao passo que a dos trabalhadores na área de serviços cresce em ritmo acelerado.

A segunda constatação é que o grupo de profissionais das áreas de serviços ocupa posições cada vez mais importantes e dominantes em relação aos produtores de bens materiais. Esses grupos "criam e controlam os conhecimentos teóricos, técnicos e práticos necessários às decisões, às inovações, ao planejamento das mudanças sociais e à gestão do crescimento cognitivo e tecnológico" (Ibidem, p. 18).

A terceira constatação é que essas atividades estão relacionadas às profissões e aos profissionais que são representantes típicos de grupos de especialistas na gestão de problemas econômicos e sociais, com o auxílio de conhecimentos fornecidos pelas ciências naturais e sociais.

E, por último, constatam que dentre as transformações em curso observa-se o crescente prestígio, nas sociedades modernas avançadas, dos ofícios e profissões que têm os seres humanos como objeto de trabalho. Essas ocupações referem-se ao trabalho relacional ou interativo, cuja principal característica é colocar em relação um trabalhador e um ser humano que utiliza seus serviços. As relações entre os trabalhadores e as pessoas constituem o processo de trabalho, o qual consiste em "manter, mudar ou melhorar a situação humana das pessoas, inclusive as pessoas elas próprias, como é o caso, por exemplo, nas terapias, na medicina, na educação, na readaptação" (TARDIF; LESSARD, 2005, p. 20). Assim, o trabalho relacional ou interativo constitui-se em um dos principais agentes de transformação da organização social e econômica contemporânea.

Nesse sentido, Tardif e Lessard salientam a centralidade dos agentes escolares na organização socioeconômica do trabalho nos principais países desenvolvidos. Tanto pelo seu número quanto pela sua função, os trabalhadores em educação constituem-se em uma das principais peças da economia das sociedades avançadas. Nessas sociedades, a educação representa, assim como o sistema de saúde, a principal carga orçamentária dos estados nacionais. O impacto da educação sobre a sociedade não se limita à economia. A educação está no coração dos processos de renovação técnico-científicas e também na partilha e distribuição dos conhecimentos e competências entre os membros da sociedade (TARDIF; LESSARD, 2005).

Dessa forma, segundo esses autores, não se sustentaria mais a visão da docência como uma ocupação secundária ou periférica em relação ao trabalho 
produtivo. Essa visão mantinha a docência subordinada à esfera da produção, pois a tinha apenas como forma principal de preparação de trabalhadores para o sistema produtivo industrial. O tempo de aprender era, simplesmente, uma preparação para a verdadeira vida, para o trabalho produtivo. Boa parte da sociologia da educação adotava esse ponto de vista, que via os docentes como trabalhadores improdutivos ou então como meros agentes de reprodução da força de trabalho capitalista (HYPOLITO, 1991; HYPOLITO, 1997).

Entretanto, a produtividade ou não do trabalho docente nas escolas públicas, sempre suscitou controvérsias. Para Marx, o trabalho docente na escola pública era considerado improdutivo, pois não tinha o objetivo de, diretamente, produzir mais-valia para o capital, no entanto, seria produtivo o trabalho de "um mestre-escola que é contratado com outros para valorizar mediante seus trabalhos, o dinheiro do empresário (...)" (MARX, 1978, p. 486).

Saviani (1987) argumenta, baseado em Marx, que o trabalho docente, de modo geral, estaria situado no âmbito da produção imaterial, no entanto "(...) os professores das escolas públicas seriam colocados do lado do trabalho improdutivo, uma vez que tais escolas seriam como entidades de prestação de serviço público" (p. 86). Já para Hypolito, "enquanto partícipe da acumulação mediata do capital este trabalho poderia ser considerado como produtivo" (1991, p. 6). Salienta também que o processo de trabalho escolar está permeado pela lógica capitalista e o"modelo de organização vigente tende, mesmo que com novas conformações, a ser generalizável e dominante em nossa sociedade" (Ibidem, p. 10).

Para Oliveira e outros (2002) a organização do trabalho escolar representa uma forma específica de organização do trabalho sob o sistema capitalista. No capitalismo, a força de trabalho, assim como o processo e os meios de trabalho, são dirigidos especificamente para a finalidade da produção de mais-valia e acumulação de capital. Dessa forma, a escola, mesmo a pública, é marcada e permeada por essa forma característica de organização da produção.

De uma maneira geral, o trabalho docente como um trabalho por natureza imaterial e pela abrangência e papel social, que assume na sociedade, é uma espécie de personificação do trabalho imaterial. Contudo, por não estar nos setores de ponta da produção, o trabalho docente não emerge como o melhor exemplo, ainda que seja uma das profissões mais antigas com essas características de trabalho.

Estudos mais recentes sobre trabalho docente demonstram que este está submetido a formas de controle e de intensificação, articuladas por modelos de organização escolar gerencial - pós-fordistas, as quais além de precarizarem e afetarem as condições físicas do trabalho, afetam igualmente aspectos emocionais e afetivos do professorado. Essas dinâmicas associadas a uma política de auditoria que pressiona as escolas e os docentes, como os grandes responsáveis pelo desempenho e pela qualidade da escola, incentivam e produzem um sentimento de culpa, que se transforma em uma verdadeira auto-intensificação do trabalho (HYPOLITO; VIEIRA; PIZZI, 2009). 
As investidas mais recentes e mais penetrantes para o controle do trabalho docente referem-se, a nosso ver, às formas de controle do conhecimento sobre o que ensinar e como ensinar. O capitalismo tenta freneticamente controlar o saber docente e o conhecimento escolar, a fim de transformar em mercadoria - na forma de materiais didáticos e métodos de ensino - tudo aquilo que é produzido pela atividade e pela prática docente (HYPOLITO, 2011).

O trabalho docente, além de ser um excelente exemplo da tendência social de hegemonia do trabalho imaterial na sociedade, é um campo de estudo a ser explorado em virtude das vastas e profundas transformações da escola e da educação no contexto de todas as transformações que se realizam na sociedade de mercado e no mundo do trabalho.

Referências

ALVES, G. O novo (e precário) Mundo do Trabalho: reestruturação produtiva e crise do sindicalismo. São Paulo: Boitempo, 2000

ANTUNES, R.; ALVES, G. As mutações no mundo do trabalho na era da mundialização do capital. Educação e Sociedade. v. 25, n. 87 Campinas: maio/ago. 2004,

ANTUNES, R. Adeus ao trabalho? Ensaios sobre as metamorfoses e a centralidade do mundo do trabalho. 5. ed. São Paulo: Cortez, 1998.

BARBOSA, M. A. de S. Demandas de formação profissional sob a ótica de empresários sergipanos: O caso do Senac. Belo Horizonte: Anais do III Simpósio de trabalho e Educação. Faculdade de Educação da UFMG, 2005.

BELL, D. O advento da sociedade pós-industrial: uma tentativa de previsão social. São Paulo: Cultrix, 1977.

BRAVERMAN, H. Trabalho e Capital Monopolista: a degradação do trabalho no século XX. 3. ed. Rio de Janeiro: Guanabara Koogan SA, 1987.

BRIDGES, W. Criando Você \& Cia: aprenda a pensar como o executivo de sua própria carreira. Rio de Janeiro: Campus, 1998.

Um Mundo sem empregos. São Paulo: Makron Books, 1995.

BURBULES, N.; TORRES, C. A. Globalização e educação: uma introdução. In: BURBULES, N.; TORRES, C. A. (Org.). Globalização e educação: perspectivas críticas. Porto Alegre: Artmed, 2004.

CASTELLS, M. A sociedade em rede. São Paulo: Paz e Terra, 1999.

COCCO, G. Estado, Mercado e Cidadania. Disponível em: <http://usuarios.lycos.es/pete_ baumann/index-68.html>. Acessado em: out. 2007.

CODO, W.; SAMPAIO, J. J.; HITOMI, A. H. Indivíduo, trabalho e sofrimento: uma abordagem interdisciplinar. Petrópolis: Vozes, 1993.

DRUCKER, P. Sociedade pós-capitalista. São Paulo: Pioneira, 2002.

GANDIN,L.A.;HYPÓLITO,Á.M.Dilemas de nosso tempo:globalização, multiculturalismo e conhecimento. (entrevista com Boaventura de Souza Santos), Currículo sem fronteiras, v. 3, n. 2, p. 5-23, jul./dez 2003. Disponível em: <www.curriculosemfronteiras.org>. Acesso em: 3 fev. 2007. 
GORZ, A. Adeus ao proletariado: para além do socialismo. Rio de Janeiro: ForenseUnivesitária, 1997.

O imaterial: conhecimento, valor e capital. São Paulo: Annablume, 2005.

HARDT, M.; NEGRI, A. Multidão. Rio de Janeiro: Record, 2005.

Império. 6. ed. Rio de Janeiro: Record, 2004.

HARVEY, D. Condição pós-moderna: uma pesquisa sobre as origens da mudança cultural. São Paulo: Loyola, 1992.

HYPOLITO, Á. M. Processo de trabalho na escola: algumas categorias para análise. Teoria \& Educação, Porto Alegre, v. 4, 1991, p. 5-21.

Trabalho docente, classes sociais e relações de gênero. Campinas : Papirus, 1997.

Reorganização gerencialista da escola e trabalho docente. Educação (Rio Claro. Online), v. 21, p. 1-18, 2011.

HYPOLITO, Á. M.; VIEIRA, J. S.; PIZZI, L.C. V. Reestruturação curricular e autointensificação do trabalho docente. Currículo sem Fronteiras, v. 9, 2009, p. 100-112.

LOJKINE, J. A Revolução Informacional. São Paulo: Cortez, 1995.

MARX, K. O Capital. v. I, Capitulo VI (Inédito). São Paulo: Livraria Editora Ciências Humanas Ltda, 1978. Brasileira, 1980

O Capital: Teorias da mais-valia. v. I, Capitulo IV, 5. ed. Rio de Janeiro: Civilização

Teses sobre Feuerbach. Disponível em: $<$ http://www.dominiopublico.gov.br/pesquisa/ DetalheObraForm.do?select_action=\&co_obra=2447 >. Acesso em: set. 2007.

MATTOSO, J. A desordem do trabalho. São Paulo: SCRITTA, 1995.

MILL, D. Educação a distância e trabalho docente virtual: sobre tecnologia, espaços, tempos, gênero e coletividade na Idade Mídia. Tese de doutorado. Belo Horizonte: Faculdade de Educação - UFMG, 2006.

MINARELLI, J. A. Empregabilidade: o caminho das pedras. São Paulo: Gente, 1995.

OFFE, C. Capitalismo desorganizado: transformações contemporâneas do trabalho e da política. São Paulo: Brasiliense, 1995,

OLIVEIRA, D. A. e outros. Transformações na organização do processo de trabalho docente e suas conseqüências para os professores. Trabalho \& Educação. Belo Horizonte: 11, jul./dez. 2002.

POCHMANN, M. Desemprego e Políticas de emprego: tendências Internacionais e o Brasil. In: OLIVEIRA, A. de. Economia \&Trabalho: Textos básicos. Campinas: Unicamp, IE, 1998.

RAMOS, M. N. A pedagogia das competências: autonomia ou adaptação. 2. ed. São Paulo: Cortez, 2002

REICH, R. B. O trabalho das nações: preparando-nos para o capitalismo do século 21. São Paulo Educator, 1994.

RIFKIN, J. O fim dos empregos: o declínio inevitável dos níveis de emprego e a redução da força global de trabalho. São Paulo: Makrom Books, 1995.

SANTOS, B. de S. Globalização e as Ciências Sociais. São Paulo. Cortez, 2002.

SAVIANI, D. Ensino público e algumas falas sobre a universidade. São Paulo: Cortez, 1987. 
TARDIF, M.; LESSARD, C. O trabalho docente: elementos para uma teoria da docência como profissão de interações humanas. Petrópolis: Vozes, 2005.

ZARIFIAN, P. Objetivo competência: por uma nova lógica. São Paulo: Atlas, 2001.

\section{Notas}

${ }^{1}$ Autonomação foi um termo inventado por Taichi Ohno, o engenheiro que desenvolveu o toyotismo. A autonomação consiste em fazer com que as máquinas e os modos de operação incluam protocolos de responsabilidade pela qualidade do produto no próprio posto de trabalho. Assim, autonomação seria a junção de autonomia + automação (ALVES, 2000).

* Professor Doutor da Universidade Federal de Pelotas - Pelotas - Rio Grande do Sul, Brasil.

** Professor do Instituto Federal Sul-Rio-grandende (IFSul) - Pelotas - Rio Grande do Sul, Brasil.

\section{Correspondência}

Álvaro Moreira Hypolito - Universidade Federal de Pelotas, Faculdade de Educação, Departamento de Ensino. Rua Alberto Rosa, 154, Centro, CEP: 96010-770 - Pelotas, Rio Grande do Sul - Brasil.

E-mail: alvaro.hypolito@gmail.com - grischke@gmail.com

Recebido em 23 de maio de 2013

Aprovado em 14 de julho de 2013 